\title{
Ubicación de la secuencia repetitiva PFCOL692 en fragmentos genómicos de Plasmodium falciparum
}

\author{
Magda E. Alvarado ${ }^{1}$, María O. Rojas ${ }^{1,2}$, Heidy Y. Guerrero ${ }^{2}$, Moisés Wasserman ${ }^{1,2}$ \\ ${ }_{1}^{1}$ Departamento de Quimica, Facultad de Ciencias, Universidad Nacional, Santa Fe de Bogotá, D.C., Colombia \\ ${ }^{2}$ Laboratorio de Bioquímica, Instituto Nacional de Salud, Santa Fe de Bogotá, D.C., Colombia
}

\section{Resumen}

Las secuencias repetitivas son componentes estructurales de los genomas eucariotes. Se desconoce la función de la mayoría de ellas, pero, al parecer, no son simplemente ADN egoísta sino que intervienen en procesos de recombinación y regulación génica. En este estudio se estableció la localización subtelomérica de la secuencia repetitiva PFCOL692 en los cromosomas de Plasmodium falciparum, a través de la caracterización de cuatro clones de la genoteca $\lambda$ EMBL4/PFCOL692, que contenían insertos entre 15 y $23 \mathrm{~Kb}$ de ADN genómico del parásito; esta caracterización se hizo mediante análisis de restricción y la posible ubicación de PFCOL692 en el genoma se exploró utilizando sondas específicas para las regiones telomérica (pTB4.1) y subtelomérica (pRep20) de los cromosomas de $P$. falciparum. El análisis de los mapas de restricción obtenidos permitió plantear una posible ubicación de PFCOL692 en el extremo de los cromosomas del parásito, donde las copias de esta secuencia se encuentran agrupadas en un segmento del subtelómero y con una posición conservada con respecto a la secuencia pRep20. Se sugiere, además, que PFCOL692 no se encuentra en el límite entre el subtelómero y el telómero.

Palabras clave: Plasmodium falciparum, secuencias repetitivas, región subtelomérica

Location of the repetitive sequence PFCOL692 in genomic fragments of Plasmodium falciparum

\begin{abstract}
In this paper we established the subtelomeric localization of the repetitive sequence PFCOL692 of Plasmodium falciparum by the characterization of four clones from a $\lambda E M B L 4 /$ PFCOL692 genomic library, which contains $15-23 \mathrm{Kbp}$ long inserts of parasite genomic DNA. Characterization was made by restriction analysis and the PFCOL692 localization in the genome was explored using specific probes for telomeric (pTB4.1) and subtelomeric regions ( $\mathrm{pRep20}$ ) of $P$. falciparum chromosomes. We proposed a possible organization for the parasite chromosomes ends, where the copies of PFCOL692 are clusters in the subtelomeric region and their localization is conserved with respect to the pRep20 sequence. In addition, we established that PFCOL692 is not located next to the telomere.
\end{abstract}

Key words: Plasmodium falciparum, repetitive sequences, subtelomeric region 
Plasmodium falciparum es el patógeno responsable de la forma más severa de malaria en el hombre. Este parásito se caracteriza por tener un ciclo de vida complejo que involucra dos hospederos en los cuales alternan dos formas de reproducción, asexual o mitótica (hospedero vertebrado) y sexual o meiótica (hospedero invertebrado); se propaga en forma haploide durante la mayor parte de su ciclo de vida. EI parásito contiene 14 cromosomas que tienen una estructura lineal convencional, caracterizada por presentar homología entre sus repeticiones teloméricas $(1,2)$; los cromosomas se encuentran funcionalmente compartimentalizados en regiones conservadas de dominio central y regiones polimórficas de dominio terminal. Los genes constitutivos (housekeeping genes) están localizados en la región central conservada del cromosoma, en tanto que los genes que codifican para proteínas inmunodominantes, como el antígeno de superficie de merozoíto (MSA) o el antígeno de eritrocito infectado con anillo (RESA), entre otros, se ubican en la región subtelomérica y polimórfica (3-7).

Adyacente al telómero, se encuentra la región subtelomérica que cubre entre 50 y $100 \mathrm{~Kb}$ a cada extremo de los cromosomas de $P$. falciparum y que contiene varias familias de ADN repetitivo no codificante y algunos genes que, por lo general, codifican para proteínas antigénicas (8-13). La función de la región subtelomérica aún no es clara, pero existen evidencias de que allí se originan importantes fenómenos como el polimorfismo cromosómico de tamaño, la variación antigénica y los diferentes fenotipos de adherencia $(3,5,13,14)$. Se ha observado, además, que in vitro, las deleciones en la región subtelomérica del cromosoma 9 disminuyen notablemente la producción de gametocitos (14).

Se considera que las secuencias repetitivas de los ADN eucariotes son componentes estructurales de los cromosomas, las cuales residen principalmente en posiciones centroméricas y teloméricas, pero su función es desconocida.

Correspondencia: Moisés Wasserman mwasserman@ hemagogus.ins.gov.co

Recibido: 02/07/99; aceptado: 21/02/00
Algunas de estas secuencias son transcritas en pequeñas moléculas de $A R N$ que tienen modificaciones en los extremos $3^{\circ}$ y $5^{\circ}(15)$. Se han propuesto algunas posibles funciones para el ADN repetitivo, por ejemplo, que el incremento en el volumen nuclear pueda aumentar la duración del ciclo de vida de la célula y que los elementos repetitivos causen recombinación ilegítima, introduzcan señales de regulación para la transcripción o nuevos sitios para el procesamiento o maduración del mARN $(13,16)$.

Las primeras secuencias repetitivas detectadas en Plasmodium, fueron reportadas en genes que codifican para antígenos como el MSA, antígeno de superficie del merozoíto y el gen RESA, antígeno de eritrocito infectado con anillo. Varios autores han asociado las secuencias repetitivas con el polimorfismo que se presenta en estas proteínas de superficie (6). Además, se han caracterizado varias secuencias repetitivas subteloméricas no codificantes de $P$. falciparum como pRep20 (17-18) y PFCOL692 (19), entre otras, y un elemento de $2,3 \mathrm{~Kb}$ de Plasmodium berghei (20).

En 1988, en el Laboratorio de Bioquímica del Instituto Nacional de Salud, se encontró una secuencia moderadamente repetitiva, específica y diferente a otras reportadas para $P$. falciparum (21-22), que tiene una longitud de $692 \mathrm{pb}$, está presente aproximadamente 60 veces en el genoma y no es una secuencia codificadora. En el análisis de ADN de $P$. falciparum procedente de cepas de Africa, Asia y América se detectó esta repetición en 11 de los 14 cromosomas con una distribución heterogénea del número de copias (19).

Los estudios posteriores que se han hecho sobre esta secuencia, denominada PFCOL692, estuvieron orientados a caracterizar las zonas adyacentes a ésta con el fin de ubicarla dentro del genoma de $P$. falciparum. Para ello, se construyó una genoteca en el fago $\lambda E M B L 4$ que permitió clonar fragmentos entre $15-23 \mathrm{~Kb}(22)$; los clones de esta genoteca se han caracterizado por tratamiento con enzimas de restricción y posterior hibridación con una sonda subtelomérica (2225). Hasta el momento, los resultados indican que PFCOL692 se ubica en la región subtelomérica de los cromosomas y por el hecho de ocupar 
regiones extensas no espaciadas por otras secuencias, se ha sugerido una organización en serie de uniones cabeza y cola. Al caracterizar uno de los clones, se encontró un marco abierto de lectura adyacente a PFCOL692, lo que permitió suponer que ésta podría estar en el límite de la región subtelomérica (23). PFCOL692 es una secuencia especifica de $P$. falciparum detectada en aislamientos provenientes de Asia, Africa y América; se hicieron amplificaciones sobre el ADN de varias cepas provenientes de estos sitios y se obtuvo un patrón uniforme de amplificación. Esto demostró que el tamaño básico de la repetición y un nivel significativo de homología se mantiene independientemente de la localización en el genoma y de la localización geográfica (19).

También se realizó análisis de restricción sobre ADN de estas cepas e hibridación con PFCOL692, encontrándose un patrón polimórfico y diferente que permite distinguir las cepas entre sí, lo que significa que PFCOL692 podría utilizarse como marcador filogenético. Sin embargo, el patrón para cepas colombianas provenientes de la misma región es muy similar y es difícil distinguirlas. Adicionalmente, esta secuencia presentó una alta sensibilidad al amplificar por PCR ADN de diferentes cepas de $P$. falciparum; se detectaron hasta $0,02 \mathrm{pg}$ de $A D N$, que equivalen a un parásito $(19,26)$. Este resultado le otorga potencial como una herramienta útil en el diagnóstico de malaria.

Este estudio se planteó con el fin de complementar la información existente acerca de la ubicación de PFCOL692 a través de la caracterización de cuatro clones más de la genoteca $\lambda E M B L 4 / P F C O L 692$, lo que nos permitió confirmar la localización subtelomérica y establecer claramente que esta secuencia no se encuentra en el límite entre el subtelómero y el telómero. La ubicación de PFCOL692 en el subtelómero aporta información importante sobre la estructura de esta región de los cromosomas del parásito, que no ha sido completamente caracterizada aún.

\section{Materiales y métodos}

Crecimiento y purificación de fagos recombinantes $\lambda E M B L 4 / P F C O L 692$ (27-28)

Se amplificaron cuatro clones de una genoteca de $P$. falciparum con la que cuenta el Laboratorio de Bioquímica (22), construida en el fago $\lambda E M B L 4$; estos clones tienen insertos de ADN con un tamaño entre $15-23 \mathrm{~Kb}$ y contienen la secuencia repetitiva PFCOL692 y regiones aledañas a ésta en el genoma. Para amplificar los clones, se infectaron bacterias Escherichia coli NM538 en LB- $0,2 \%$ maltosa. La mezcla se incubó a $37^{\circ} \mathrm{C}$; para permitir la adsorción del fago a la bacteria, se mezcló con Top-0,7\% agarosa- $10 \mathrm{mM} \mathrm{MgSO}_{4}$ (Agarosa MERCK) a $50{ }^{\circ} \mathrm{C}$ y se incubó hasta obtener una lisis confluente. La recuperación de los fagos se hizo por agitación de las cajas confluentes con buffer SM $(50 \mathrm{mM}$ Tris- $\mathrm{HCl}, \mathrm{pH}$ 7,5, $100 \mathrm{mM} \mathrm{NaCl}, 8 \mathrm{mM} \mathrm{MgSO}_{4}, 0,01 \%$ gelatina) durante 6 horas a $4^{\circ} \mathrm{C}$ y posterior centrifugación a $8.000 \mathrm{~g}$ durante 10 minutos a $4{ }^{\circ} \mathrm{C}$ (centrífuga HIMAC SCR20BA rotor RPR20-2), con el fin de eliminar restos bacterianos y Top-agarosa; el lisado de fagos así obtenido, se almacenó a $4{ }^{\circ} \mathrm{C}$ en presencia de cloroformo al 0,3\% (v/v).

\section{Extracción de $A D N$ de clones de la genoteca $\lambda E M B L 4$}

Para la extracción de ADN de los lisados amplificados de cada uno de los clones, se utilizó el método comercial Lambda Sorb Phage Adsorbent (Promega) modificado; la modificación consistió en la adición de un tratamiento de los fagos con proteinasa $K$, después de $\mathrm{I}$ : precipitación con anticuerpos contra lambda. Est tratamiento aseguró la destrucción de la cápside de los fagos y la liberación del ADN recombinante y mejores porcentajes de recuperación del mismo. En resumen, $10 \mathrm{ml}$ del lisado de fagos se mezclaron con $100 \mu \mathrm{l}$ de un anticuerpo específico contra el fago, denominado comercialmente Lambda Sorb, durante 30 minutos a temperatura ambiente con agitación a $150 \mathrm{rpm}$. Los fagos unidos al anticuerpo se recuperaron por centrifugación a $14.000 \mathrm{~g}$ por 15 minutos a $4^{\circ} \mathrm{C}$. El precipitado se lavó dos veces con $1 \mathrm{ml}$ de buffer SM en una microcentrífuga Eppendorf a 12.000 rpm por 2 minutos. El fago precipitado se resuspendió en un buffer $10 \mathrm{mM} \mathrm{NaCl}, 50 \mathrm{mM}$ Tris pH 7,8. Se adicionó 0,5M EDTA, $50 \mu \mathrm{g} / \mathrm{ml}$ proteinasa $\mathrm{K}$ y $0,5 \%$ SDS (29). La reacción se llevó a cabo a $56^{\circ} \mathrm{C}$ durante una hora. Se retiró el adsorbente por centrifugación a 5.000 rpm durante 
cinco minutos en una microcentrífuga Tomy HF120 a temperatura ambiente. Al sobrenadante se le hizo extracción fenólica y precipitación alcohólica. EIADN se recuperó por centrifugación durante 1 hora a $14.000 \mathrm{rpm}$ y $4{ }^{\circ} \mathrm{C}$ en una microcentrífuga Eppendorf; se lavó con $1 \mathrm{ml}$ de etanol al $70 \%$ para retirar sales; se secó al vacío durante 10 minutos y se resuspendió en buffer TE. La cantidad de ADN recuperado se cuantificó en geles de agarosa al $1 \%$.

\section{Mapeo de restricción}

Digestión enzimática del $A D N$. Se realizaron digestiones simples con las enzimas EcoRI (Promega), Haelll (BRL), Hincll (BRL) y digestiones dobles con las combinaciones EcoRI/ Haelll, EcoRI/Hincll y Haelll/Hincll. Las condiciones de reacción fueron las recomendadas por el fabricante de la enzima. En las digestiones simples, se cortaron $200 \mathrm{ng}$ de ADN de cada clon y se utilizaron $10 \mathrm{U}$ de enzima por cada reacción en un volumen final de $10 \mu \mathrm{l}$. Para las digestiones dobles, se tomaron $400 \mathrm{ng}$ de ADN; de cada clon se hizo la primera digestión, luego se tomó una alícuota de esta reacción, que contenía 100 ng de ADN para hacer control de la eficiencia de corte; el volumen restante de la reacción se completó a $100 \mu \mathrm{l}$ con TE y se hizo una extracción fenólica para retirar la enzima. Después, se hizo una precipitación etanólica y el ADN se resuspendió en $8 \mu \mathrm{l}$ de TE y sobre éstos se realizó la segunda digestión en las mismas condiciones utilizadas para el primer corte. Se corrió una electroforesis de los productos de la reacción enzimática de cada uno de los clones en gel de agarosa al $1 \%$ para visualizar los resultados; el gel se reveló con una solución acuosa $(0,5 \mu \mathrm{g} / \mathrm{ml})$ de bromuro de etidio durante 30 minutos y se observó bajo luz UV de $302 \mathrm{~nm}$.

Transferencia de ADN a membranas de nylon (29). Se transfirió el ADN de cada clon digerido enzimáticamente a membrana de nylon (Hybond) mediante vacío en una unidad de transferencia (LKB); el gel se orientó adecuadamente para evitar burbujas y elADN se depurinó por tratamiento con $0,25 \mathrm{~N} \mathrm{HCl}$; seguidamente, se trató con una solución $0,5 \mathrm{~N}$ de $\mathrm{NaOH}$ y $0,15 \mathrm{M} \mathrm{NaCl}$ para denaturar el ADN durante un tiempo similar al que se necesitó en la depurinación. La neutralización se realizó por tratamiento con una solución $1 \mathrm{M}$ Tris, $\mathrm{pH} 7,5,1,5 \mathrm{M} \mathrm{NaCl}$ durante el mismo tiempo. La transferencia se hizo con 20XSSC $(17,5 \% \mathrm{NaCl}$, $8,8 \%$ de citrato de sodio, $\mathrm{pH} 7,0$ ). La membrana se sumergió durante 10 minutos en una solución 20XSSC a temperatura ambiente con el fin de eliminar residuos de agarosa; se dejó secar a temperatura ambiente y el ADN se fijó por exposición a luz UV de 254 nm durante un minuto.

Reconocimiento de la presencia de secuencias subteloméricas y teloméricas en los insertos mediante hibridación con sondas radiactivas de $A D N$. Para establecer en cada clon cuáles de los fragmentos de digestión contenían la repetición PFCOL692 y si existía alguna relación entre esta secuencia y las regiones teloméricas y subteloméricas de los cromosomas del parásito, se marcaron radiactivamente las sondas PFCOL692, la sonda pRep20, ampliamente utilizada como marcador del subtelómero en numerosos estudios $(17-18,30)$, que proviene de una cepa de Tanzanía de $P$. falciparum y tiene una longitud de $1,5 \mathrm{~Kb}$, y la sonda telomérica pTB4.1 (1-2,30), que proviene de P. berguei, que contenia varias copias de la secuencia específica del telómero (TTT/CAGGG) para el género Plasmodium y tiene una longitud de $500 \mathrm{pb}$. Para detectar las secuencias homólogas presentes en los insertos, por hibridación se marcaron radiactivamente las sondas por el método Random Primer, utilizando el sistema Prime-a-gene Labeling System (Promega). Se marcaron $100 \mathrm{ng}$ de ADN de cada sonda a $500 \mathrm{ng} / \mathrm{ml}$, en presencia de $20 \mu \mathrm{M} \mathrm{d}(\mathrm{G}, \mathrm{C}, \mathrm{T})$ sin marcar, $333 \mathrm{nM}\left[{ }^{35} \mathrm{~S}\right] \alpha \mathrm{dATP}$ $1.000 \mathrm{Ci} / \mathrm{mmol}$ (ICN), $26 \mathrm{~A}_{260}$ unidades $/ \mathrm{ml} \mathrm{de}$ hexanucleótidos en el buffer de marcación (250 mM Tris- $\mathrm{HCl}, \mathrm{pH} \mathrm{8,0;} 25 \mathrm{mM} \mathrm{MgCl}, 10 \mathrm{mM}$ DTT, $1 \mathrm{M}$ Hepes $\mathrm{pH} 6,6), 400 \mu \mathrm{g} / \mathrm{ml}$ de BSA y $100 \mathrm{U} / \mathrm{ml}$ de ADN polimerasa I, fragmento Klenow. La reacción se llevó a cabo durante toda la noche a $37^{\circ} \mathrm{C}$; se detuvo por enfriamiento a $4{ }^{\circ} \mathrm{C}$ y se determinó el porcentaje de incorporación (29).

Se utilizaron $2 \times 10^{8}$ cuentas por minuto de la sonda para detectar los fragmentos homólogos por Southern blot; se hizo una prehibridación en 6 XSSC $(5,25 \% \mathrm{NaCl}, 2,64 \%$ de citrato de sodio, $\mathrm{pH} 7,0), 10 \mathrm{X}$ Denhardt $(0,2 \%$ ficoll $400,0,2 \%$ 
polivinilpirrolidina, $0,2 \% \mathrm{BSA}$ ), $5 \%$ sulfato de dextrán, $50 \%$ de formamida y $100 \mu \mathrm{g} / \mathrm{ml}$ de ADN de esperma de salmón y se incubó entre 2 y 16 horas a $42{ }^{\circ} \mathrm{C}$. Para la sonda PFCOL692, la temperatura de hibridación fue de $41^{\circ} \mathrm{C}$; para la sonda telomérica pTB $4.1,45^{\circ} \mathrm{C}$ y para la sonda subtelomérica pRep20, $44,2^{\circ} \mathrm{C}$ durante 14 horas. Las membranas se lavaron con 6 XSSC, $0,1 \%$ SDS a temperatura ambiente, luego con 2 XSSC, $0,1 \%$ SDS a temperatura ambiente durante 15 minutos $y$, finalmente, se hicieron dos lavados en 0,1 XSSC, $0,1 \%$ SDS a temperatura ambiente durante 15 minutos. Después de secar las membranas a temperatura ambiente, se expusieron sobre papel de autorradiografía hyperfilm $\beta$ Max (Amersham) a $-70{ }^{\circ} \mathrm{C}$ durante 48 horas; si al cabo de este tiempo no se observaban señales claras, se aumentaba el tiempo de exposición a 90 horas. La reutilización de las membranas con varias sondas, se hizo después de tratamiento en $100 \mathrm{ml}$ de una solución $0,1 \%$ SDS a $92^{\circ} \mathrm{C}$ durante 60 minutos.

\section{Resultados y discusión}

\section{Extracción de ADN}

Se obtuvieron, aproximadamente, $4 \mu \mathrm{g}$ de ADN de cada uno de los clones, cantidad que no era suficiente para liberar el inserto, purificarlo y hacer las restricciones enzimáticas. Por esta razón, se decidió trabajar con el ADN del clon completo (incluidas las secuencias del vector) para hacer los análisis de restricción, evitando las pérdidas de material que implicaban los procedimientos mencionados. Debido a esto, los análisis de los productos de restricción debían incluir la eliminación de las bandas correspondientes al vector; para ello, se tomaron las secuencias de los brazos de $\lambda E M B L 3$, que son las informadas en el Genebank y son iguales a las de $\lambda E M B L 4$. Mediante el programa DNAsis y las bases de datos del Genebank, se hallaron los sitios de corte EcoRI, Haelll y Hincll sobre el vector y se determinaron los tamaños de los fragmentos que debían ser descartados de los patrones de digestión de cada clon. Estos fragmentos son: $1,3,1,0,0,9,0,8,0,7,0,6$ y $0,5 \mathrm{~Kb}$ provenientes de la digestión con Haelll; 5,3, 4,5, 2,2, 2,1, 2,0, $1,7,1,3,1,2,1,1,0,9,0,8,0,6$ y $0,5 \mathrm{~Kb}$ provenientes de la digestión con Hincll. El vector no contenía sitios de corte con EcoRI.

\section{Southern blots}

Las membranas a las que se transfirió la electroforesis de los fragmentos de restricción (figura $1 \mathrm{~A})^{\star}$ para cada clon se hibridizaron con las sondas marcadas radiactivamente; con la sonda PFCOL692, se generaron múltiples señales de hibridación, intensas y discretas en los cuatro clones estudiados como se puede observar en la autorradiografía del ejemplo ilustrado en la figura $1 \mathrm{~B}$, lo cual refleja la presencia de más de una copia de esta secuencia en los clones. La hibridación con la sonda subtelomérica pRep20 específica de $P$. falciparum, se caracterizó en todos los clones por generar pocas y débiles señales en las autorradiografías, como se muestra en la figura $1 \mathrm{C}$, lo que estaba indicando un bajo número de copias de esta secuencia en los insertos. Con la sonda telomérica pTB4.1, que contenía varias copias de la secuencia específica del telómero (TTT/CAGGG) para el género Plasmodium, se hibridizaron once clones, los cuatro que se caracterizaron en este trabajo y siete adicionales que se habian caracterizado en un trabajo anterior (24). En ninguno de los clones estudiados se obtuvieron señales de hibridación con esta sonda. Este resultado se constituye en una fuerte evidencia de que los insertos que contienen a PFCOL692, no se encuentran adyacentes al telómero en los cromosomas de $P$. falciparum. Con base en el hecho de que ninguno de los insertos hibridizó con la sonda telomérica, se puede decir que en los segmentos clonados donde se encuentran las secuencias aledañas a la repetición PFCOL692 no se encuentran presentes secuencias teloméricas.

\section{Construcción de los mapas de restricción}

Los resultados de la hibridación con las sondas radiactivas indicaron claramente que PFCOL692 estaba físicamente cercana a la secuencia subtelomérica pRep20. Para establecer cómo se relacionaban estas secuencias en los insertos, se construyeron sus mapas físicos. Analizando los resultados obtenidos a partir de las diferentes digestiones sobre el DNA de cada clon. Los productos de digestión se separaron por tamaños

\footnotetext{
* Sólo se presentan los resultados para el clon 28R, los otros tres clones se comportan de forma similar.
} 


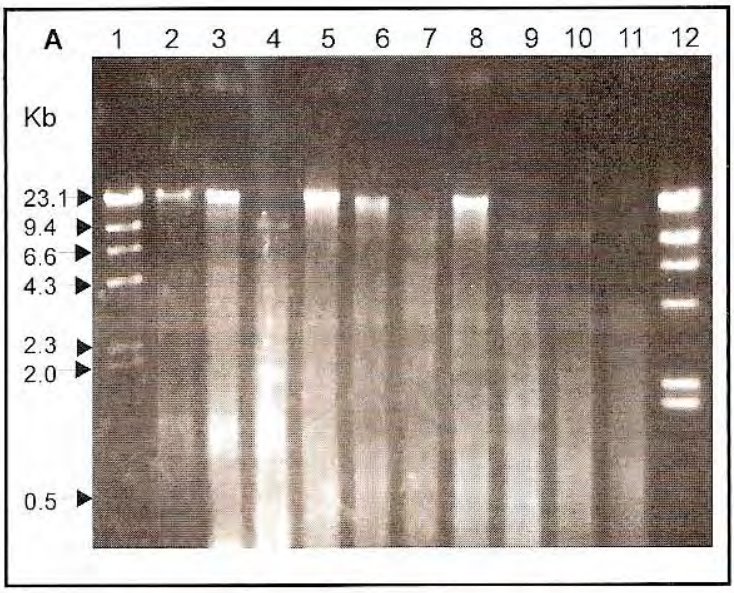

Figura 1A. Patrones de restricción e hibridación del clon $28 \mathrm{R}$. Fotografía de una electroforesis en agarosa $1 \%$ teñida con bromuro de etidio donde se muestran los resultados de la digestión de $200 \mathrm{ng}$ de ADN 28R con diferentes enzimas de restricción. Carril 1 y 12, marcador de tamaño lambda Hind III; carril 2, ADN 28R sin digestión; carril 3, ADN 28R/EcoRI; carril 4, ADN 28R/Haelli; carril 5, ADN 28R/ Hincll; carril 6 y 8 ADN 28R/EcoRI (control de la primera digestión); carril 7, ADN 28R/EcoRI/Hincll; carril 9, ADN 28R/ EcoRI/Haelli; carril 10, ADN 28R/Haelll (control de la primera digestión); carril 11, ADN 28R/Haelll/Hincll.

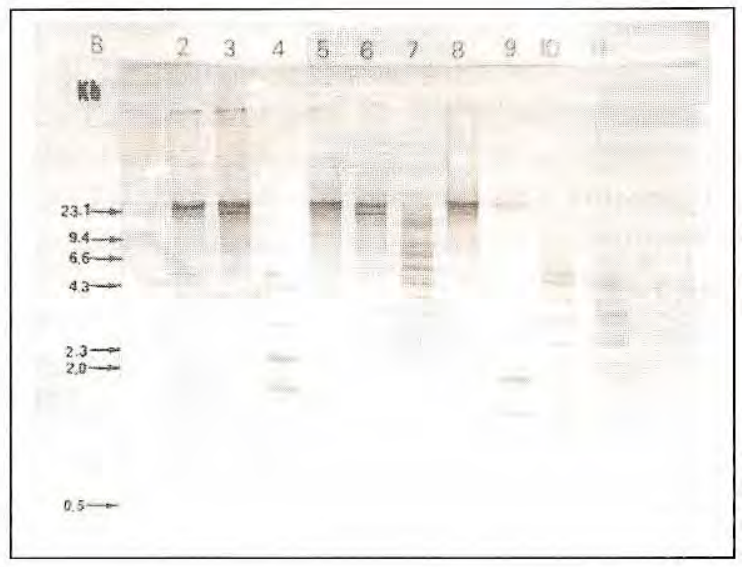

Figura 1B. Patrones de restricción e hibridación del clon 28R. Autorradiografía de la electroforesis que se muestra en $A$, transferida a membrana e hibridada con la sonda radiactiva PFCOL692. Las señales se observan después de lavados de alta astringencia y exposición de $48 \mathrm{~h}$ a -70 ${ }^{\circ} \mathrm{C}$ de la membrana.

en una electroforesis en agarosa y se visualizaron por tinción con bromuro de etidio bajo luz UV. En cada uno de los cuatro clones estudiados, se analizaron de forma independiente los patrones

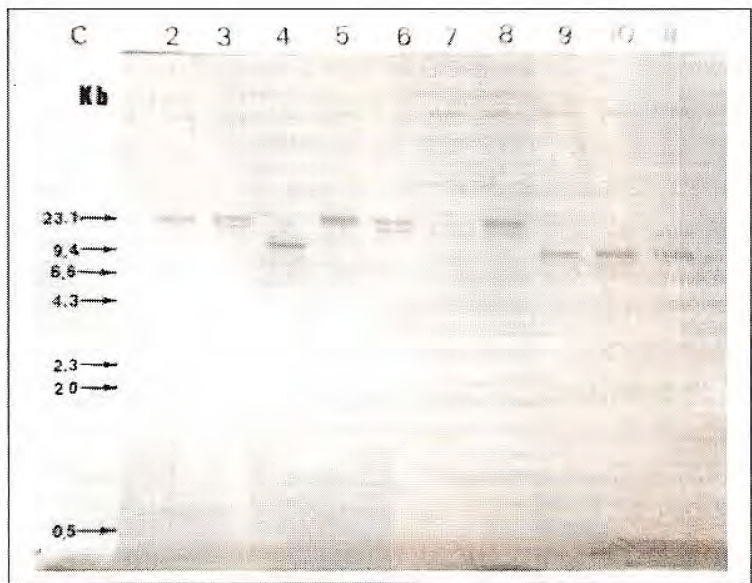

Figura 1C. Patrones de restricción e hibridación del clon 28R. Autorradiografía de la electroforesis que se muestra en $\mathrm{A}$, hibridada con la sonda radiactiva $p R e p 20$ después de lavados de alta astringencia y exposición de $48 \mathrm{~h}$ a $-70^{\circ} \mathrm{C}$ de la membrana.

obtenidos para cada restricción. Se tuvieron en cuenta, además, los resultados de estudios anteriores sobre PFCOL692 (19), donde se estableció que usualmente las copias de esta secuencia se organizan una seguida de la otra formando una serie; por ello, en principio se asumió que los fragmentos que hibridaron con la sonda PFCOL692 se encontraban seguidos en el inserto, y conociendo el tamaño de la secuencia (692 pb) se estimó el número de copias presente. También se observó que todos los clones caracterizados en este trabajo hibridaron con la sonda subtelomérica, pero ningún fragmento presentó hibridación cruzada con las sondas PFCOL692 y pRep20, lo cual estaba indicando que estas dos secuencias se encontraban cerca pero no contiguas o sobrelapadas en los insertos y que estaban separadas entre si por las secuencias que no hibridaron con ninguna de ellas.

El análisis anterior se tomó como base para construir los esquemas o mapas físicos de los insertos, pero cada uno de ellos se fue adaptando de acuerdo con los resultados hasta obtener el esquema que explicara o justificara los fragmentos obtenidos en las restricciones y las señales generadas por la hibridación con cada sonda; se tuvo en cuenta, además, que el tamaño del inserto no podía ser menor de $15 \mathrm{~Kb}$ ni mayor de $23 \mathrm{~Kb}$ 
Figura 2. Mapas de restricción de los clones $\lambda$ EMBL4/PFCOL692 obtenidos por digestiones simples y combinadas con las enzimas EcoRl, Haell y Hincll. La barra gruesa representa el inserto; en azul, el segmento que contiene la secuencia PFCOL692; en negro, el segmento del inserto que no hibridó con ninguna de las tres sondas utilizadas en este trabajo y, en rojo, el segmento que contiene la secuencia pRep20. Las lineas delgadas indican cuáles fueron los fragmentos obtenidos en las restricciones; el número en la línea indica el tamaño en Kb; las letras E: EcoRI, C: Hincll, H: HaellI, señalan con cuáles enzimas fueron generados y el color de la línea con cuál sonda hibridaron dichos fragmentos: negro con ninguna, azul con PFCOL692 y rojo con pRep20.

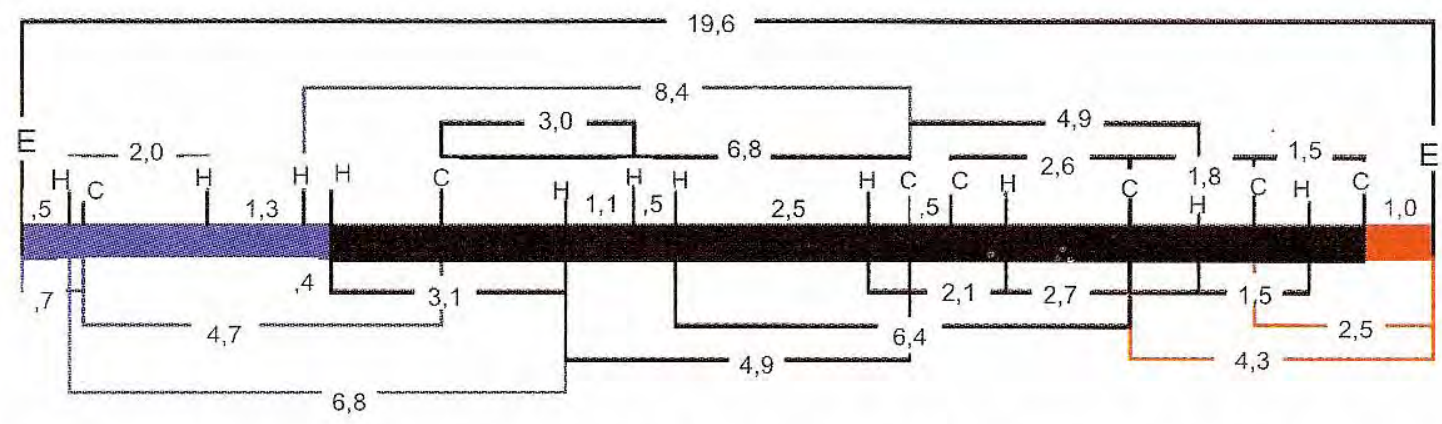

2A. Organización física y de restricción del clon 11R; tamaño del inserto, 19,6 Kb; PFCOL692 ocupa 4,2 Kb; las secuencias que no hibridan, $14,4 \mathrm{~Kb}$ y pRep20 ocupa $1 \mathrm{~Kb}$.

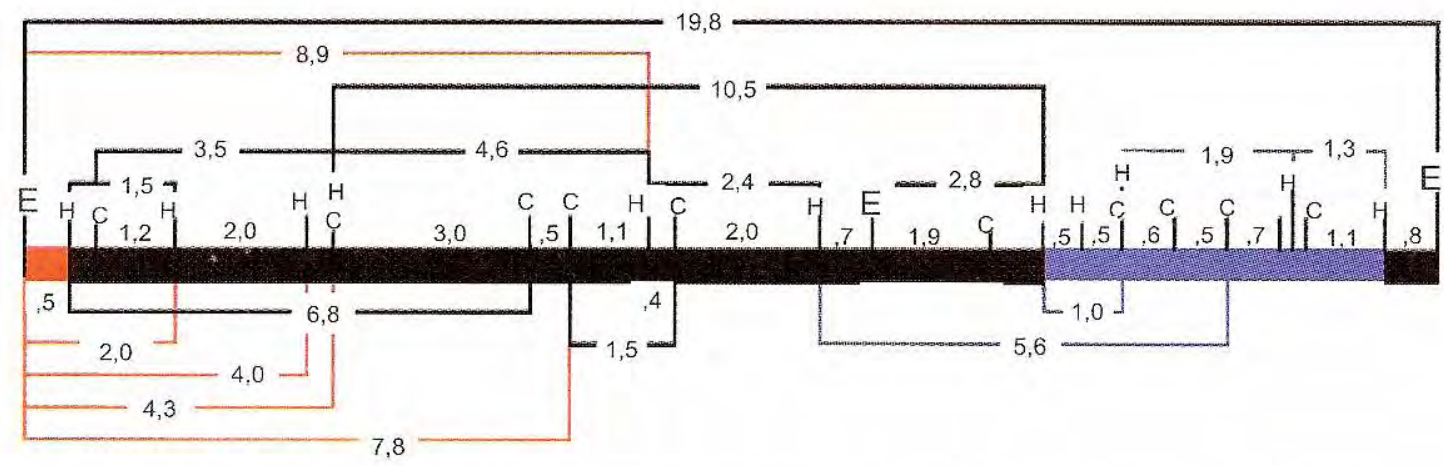

2B. Organización física y de restricción del clon 20R; tamaño del inserto 19,8 Kb; PFCOL692 ocupa 4;2 Kb; las secuencias que no hibridan, $15,1 \mathrm{~Kb}$ y pRep20 ocupa $0,5 \mathrm{~Kb}$.

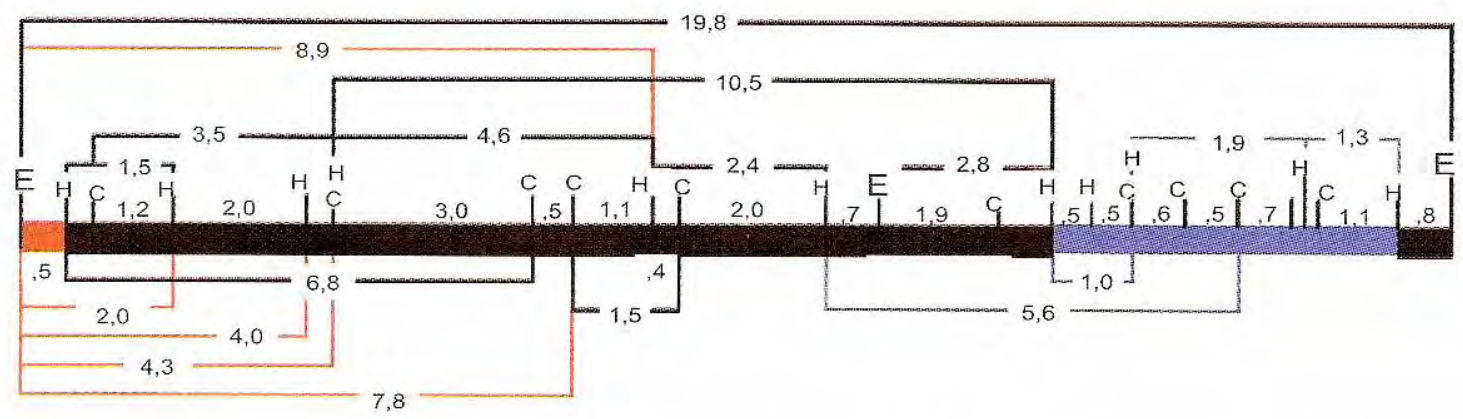

2C. Organización física y de restricción del clon 22R; tamaño del inserto $23,7 \mathrm{~Kb}$; PFCOL692 ocupa 10,7 Kb; las secuencias que no hibridan, aproximadamente, $9,2 \mathrm{~Kb}$ y pRep2 0 no se puede estimar porque al parecer en las restricciones es reducida a tamaños menores de $0,5 \mathrm{~Kb}$ que no son detectados en un gel de agarosa al $1 \%$. 


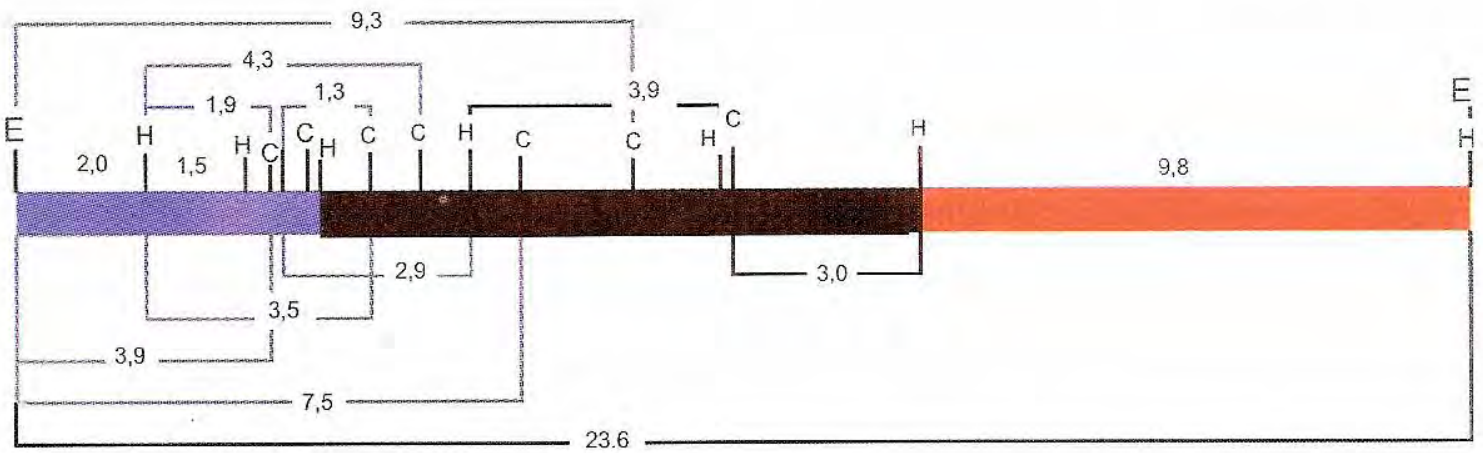

2D. Organización física y de restricción del clon 28R; tamaño del inserto, $236 \mathrm{~Kb}$; PFCOL692 ocupa 4,6 Kb; las secuencias que no hibridan, $9,2 \mathrm{~Kb}$ y pRep20 está presente en un fragmento de $9,8 \mathrm{~Kb}$, pero su tamaño real no se puede estimar porque este fragmento no tiene sitios internos de corte para las enzimas utilizadas en este estudio.

por ser éste el tamaño confirmado para los clones de la genoteca. Luego de tener los mapas que explicaran por separado las restricciones con Haelll y Hincll, se sobrelaparon para comprobar que el análisis era coherente; de esta manera, sobre el mapa resultante se podían justificar los cortes generados en la digestiones dobles Haelll/ Hincll, EcoRI/Hincll y EcoRI/HaellI. En las figuras 2A-2D se presentan los mapas físicos y de restricción de los cuatro clones, donde se indican los sitios de corte de cada enzima, el tamaño de los fragmentos y los resultados de las diferentes hibridaciones.

\section{Posible ubicación de PFCOL692 en el subtelómero}

Los mapas físicos y de restricción de los cuatro insertos caracterizados presentaron una organización similar, en la que PFCOL692 se encuentra agrupada a un extremo del inserto ocupando regiones de más de $3 \mathrm{~Kb}$; en tanto que pRep20 se localiza al otro extremo ocupando regiones de menos de $1 \mathrm{~Kb}$. En el centro del inserto, separando estas dos secuencias, se encuentra una región de aproximadamente $10 \mathrm{~Kb}$ que no hibridó con ninguna de las tres sondas utilizadas en este trabajo. Esta organización muestra una localización conservada entre PFCOL692 y pRep20, lo cual es muy interesante puesto que se sabe que pRep20 está presente en el subtelómero de todos los cromosomas de $P$. falciparum, ocupando regiones extensas ( $1 \%$ del genoma aproximadamente) y que tiene una localización relativamente conservada cerca al telómero $(5,17,18,30)$.

La posibilidad de una posición conservada de PFCOL692 con respecto a pRep20 está confirmando la localización en el subtelómero de PFCOL692, y el hecho de que los patrones de restricción sean diferentes para cada clon, indica que provienen de diferentes contextos en el genoma y que, posiblemente, estos insertos corresponden a extremos de diferentes cromosomas. Lo anterior, permite plantear que la secuencia PFCOL692 no se encuentra dispersa en el subtelómero sino que se encuentra agrupada en un pequeño segmento de esta región y su localización se conserva entre los diferentes finales de los cromosomas. El hecho de que ninguno de los 11 clones analizados contenga secuencias teloméricas, permite establecer claramente que PFCOL692 definitivamente es una secuencia subtelomérica, y que no se encuentra unida directamente al telómero.

Finalmente, confirmamos la presencia de PFCOL692 en la región subtelomérica de los cromosomas 2 y 3 (31-32), cuyas secuencias fueron recientemente reportadas, utilizando Plasmodium falciparum Genome Database Chromosome 2 y The Sanger Center Blast Server Result. Se realizó una búsqueda sobre los cromosomas completos y se encontró a PFCOL692 exclusivamente en la región subtelomérica, ocupando aproximadamente $2 \mathrm{~Kb}$ en ambos extremos y separada de pRep20 por $6 \mathrm{~Kb}$ en el 


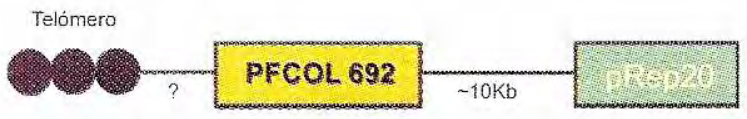

Figura 3. Posible ubicación de la secuencia repetitiva PFCOL692 en los cromosomas de P. falciparum. La posición de $\mathrm{pRep} 20$ se definió de acuerdo con los datos de la literatura $(5,17,18,31,32)$ y la posición relativa de PFCOL692 fue el resultado del presente estudio.

cromosoma 2 y $9 \mathrm{~Kb}$ en el cromosoma 3. Presentamos un esquema donde se resume todo lo discutido anteriormente y se plantea una posible organización para el final de los cromosomas de $P$. falciparum en la figura 3 , que está de acuerdo con lo informado recientemente, pero que solamente es una posibilidad ya que el subtelómero es una región muy variable. Estos resultados son interesantes porque, teniendo en cuenta lo informado por Hernández-Rivas y colaboradores en 1997 (13), quienes encontraron una copia transcripcionalmente activa de un gen Var flanqueando el lado derecho de pRep20 sobre los cromosomas 3 y 11 en la cepa FCR3 y, conociendo la relación entre PFCOL 692 y pRep20, existe la probabilidad de que en la genoteca $\lambda \mathrm{EMBL} 4 \mathrm{y}$, específicamente en los clones analizados en este trabajo, se encuentre clonada alguna copia de la gran familia multigénica Var. Esta posibilidad está fundamentada en el tamaño de los insertos (15-23 Kb) y en que la región espaciadora entre pRep20 y PFCOL692 es conservada y tiene un tamaño promedio de 10 $\mathrm{Kb}$, donde podría estar una copia de un gen var que, en promedio, cubre $9 \mathrm{~Kb}$.

\section{Conclusiones}

Los resultados obtenidos en este estudio, complementaron la información que se tenía sobre la secuencia repetitiva PFCOL692, lo cual permitió hacer un aporte al conocimiento básico de la estructura del extremo de los cromosomas de $P$. falciparum, lo que es indispensable para pasar a consideraciones sobre el posible papel biológico de PFCOL692 en el genoma del parásito.

Existen fuertes evidencias que indican que en el subtelómero ocurren importantes fenómenos, como los rearreglos asociados con el polimorfismo en tamaño de los cromosomas, la variación en la expresión de proteínas inmunodominantes y de adherencia, y en la diferenciación de los merozoítos a gametocitos en el estadio asexual sanguíneo. La localización conservada de PFCOL692 en el subtelómero, la proyecta como una de las secuencias comprometidas en los procesos mencionados, de gran importancia en el ciclo de vida del parásito y en su virulencia.

\section{Agradecimientos}

Este proyecto fue financiado por el Instituto Colombiano para el Desarrollo de la Ciencia y la Tecnología Francisco José de Caldas, Colciencias, proyecto 2104-04-170-95, y por el Instituto Nacional de Salud.

\section{Referencias}

1. Dore E, Pace T, Ponzi M, Scotti R and Frontali C. Homologous telomeric sequences are present in different species of the genus Plasmodium. Mol Biochem Parasitol 1986;21:121-7.

2. Vernick KD, McCutchan TF. Sequence and structure of a Plasmodium faiciparum telomere. Mol Biochem Parasitol 1988;28:85-94.

3. Ravetch JV. Chromosomal polymorphisms and gene expression in Plasmodium falciparum. Exp Parasitol 1989;68:121-5.

4. Lanzer M, de Bruin D, Wertheimer S and Ravetch JV. Transcriptional and nucleosomal characterization of a subtelomeric gene cluster flanking a site of chromosomal rearrangements in Plasmodium falciparum. Nucleic Acids Res 1994;22:4176-82.

5. Scherf A. Plasmodium telomeres and telomere proximal gene expression. Sem Cell Develop Biol 1996;7:4957.

6. Lanzer M, de Bruin D, Wertheimer SP, and Ravetch JV. Organization of chromosomes in Plasmodium falciparum: a model for generating karyotypic diversity. Parasitol Today 1994;10:114-27.

7. Vernick KD, Walliker D and Mc Cutchan TF. Genetic hypervariability of telomere-related sequences is associated with meiosis in Plasmodium falciparum. Nucleic Acids Res 1988;16:6973-85.

8. De Bruin D, Lanzer M \& Ravetch JV. The polymorphic subtelomeric regions of Plasmodium falciparum chromosomes contain arrays of repetitive sequence elements. Proc Nat Acad Sci USA 1994;91:619-23.

9. Hinterberg K, Mattei D, Wellems TE and Scherf A. Interchromosomal exchange of a large subtelomeric segment in a Plasmodium falciparum cross. EMBO J 1994;13:4174-80.

10. Scherf A, Mattei D. Cloning and characterization of chromosome breakpoints of Plasmodium falciparum: 
breakage and new telomere formation occurs frequently and randomly in subtelomeric genes. Nucleic Acids Res 1992;20:1491-6.

11. Mattei D, Scherf A. Subtelomeric chromosome instability in Plasmodium falciparum: short telomere-like sequence motifs found frecuently at healed chromosome breakpoints. Mutation Res 1994;324:115-20.

12. Dolan SA, Herrfeldt JA, Wellems TE. Restriction polymorphism and fingerprint patterns from an interspersed repetitive element of Plasmodium falciparum DNA. Mol Biochem Parasitol 1993;61:137-42.

13. Hernandez-Rivas R, Mattei D, Sterkers Y, Peterson DS, Wellems TE and Sherf A. Expressed var genes are found in Plasmodium falciparum subtelomeric regions. Mol Cell Biol 1997; 17:604-11.

14. Bourke PF, Holt DC, Sutherland CJ, Kemp DJ. Disruption of a novel open reading frame of Plasmodium falciparum chromosome 9 by subtelomeric and internal deletions can lead to loss or maintenance of cytoadherence. Mol Biochem Parasitol 1996;82:25-36.

15. Jelinek WR, Schmid CW. Repetitive sequences in eukaryotic DNA and their expression. Ann Rev Biochem 1982;51:813-44.

16. Elder FJ, Turner BJ. Concerted evolution of repetitive DNA sequences in eukaryotes. Quart Rev Biol 1995;70: 297-320.

17. Aslund L, Franzén L, Westin G, Persson T, Wigzell $H$, Pettersson $U$. Highly reiterated non-coding sequence in the genome of Plasmodium falciparum is composed of 21 base-pair tandem repeats. $\mathrm{J}$ Mol Biol 1985:185:509-16.

18. Oquendo P, Goman M, Mackay M, Langsley G, Walliker D, Scaife J. Characterisation of a repetitive DNA sequence from the malaria parasite, Plasmodium falciparum. Mol Biochem Parasitol 1986;18:89-101.

19. Wasserman M, Contreras J, Pinilla G, Rojas MO, Páez A, Caminos E. Plasmodium falciparum: characterization of a $0.7 \mathrm{kbp}$, moderately repetitive sequence. Exp Parasitol 1995;81:165-71.

20. Pace T, Ponzi M, Dore E, Frontali C. Telomeric motifs are present in a highly repetitive element in the Plasmodium berguei genome. Mol Biochem Parasitol 1987; 24:193-202.

21. Mantilla JR. Construcción de una biblioteca genómica de Plasmodium falciparum e identificación de clones por hibridización (tesis). Bogotá: Universidad Nacional de Colombia; 1988.

22. Contreras J, Wasserman M. Construcción de una genoteca de Plasmodium falciparum en el fago Lambda EMBL-4 y aislamiento de clonos que contienen la secuencia repetitiva de 692 pares de bases (PFCOL692). Biomédica 1993;13:65-70.

23. Polanco JC. Caracterización del DNA vecino a la secuencia repetitiva PFCOL692 de Plasmodium falciparum (tesis). Santa Fe de Bogotá: Universidad Nacional de Colombia; 1995.

24. Iriarte R. Estudio de la secuencia repetitiva PFCOL 692 de Plasmodium falciparum mediante hibridización de los clones de una genoteca en $\lambda \mathrm{EMBL} 4$ (tesis). Santa Fe de Bogotá: Universidad Nacional de Colombia; 1996.

25. Paéz A. Estudio de localización de la secuencia repetida PFCOL692 dentro del genoma de Plasmodium falciparum por análisis de restricción de fragmentos de $15 \mathrm{kpb}$ (tesis). Santa Fe de Bogotá: Universidad Nacional de Colombia; 1993.

26. Pinilla G. Evaluación de métodos de marcación radiactivos y no radiactivos en la elaboración de sondas diagnósticas de malaria (tesis). Santa Fe de Bogotá: Universidad Nacional de Colombia; 1992.

27. Ausubel FM, Brent R, Kingston RE, Moore DD, Seidman JG, Struhl K, editors. Current protocols in molecular biology. Massachusetts General Hospital and Harvard Medical School. Boston: John Wiley \& Sons; 1995. p.1.9.1-1.13.7.

28. Sambrook J, Fritsh EF, Maniatis T. Molecular cloning: a laboratory manual. New York: Cold Spring Harbor Laboratory Press; 1989. p.55-68.

29. Rojas MO, Contreras J, Pinilla G, Beltrán R, Wasserman M. Biología molecular. Manual de técnicas básicas. Santa Fe de Bogotá: Instituto Nacional de Salud; 1994. p.18.

30. Patarapotikul J, Langsley G. Chromosome size polymorphism in Plasmodium falciparum can involve deletions of the subtelomeric pPFrep20 sequence. Nucleic Acids Res 1988;16:4331-40.

31. Gardner MJ, et al. Chromosome 2 sequence of the human malaria parasite Plasmodium falciparum. Science 1998;282:1126-32.

32. Bowman $\mathbf{S}$, et al. The complete nucleotide sequence of chromosome 3 of Plasmodium falciparum. Nature 1999;400:532-8. 